\title{
Simultaneous determination of insulin and its analogues in pharmaceutical formulations by micellar electrokinetic chromatography
}

\author{
Caroline Lamalle ${ }^{\mathrm{a}}$, Anne-Catherine Servais ${ }^{\mathrm{a}}$, Régis P. Radermecker ${ }^{\mathrm{b}}$, \\ Jacques Crommen ${ }^{a}$, Marianne Fillet ${ }^{\mathrm{a}, *}$ \\ a Laboratory of Analytical Pharmaceutical Chemistry, Department of Pharmacy, CIRM, University of Liege, CHU, B36, B-4000 Liege, Belgium \\ ${ }^{\mathrm{b}}$ Department of Diabetes, Nutrition and Metabolic disorders, CHU Sart Tilman, University of Liege, Belgium
}

\section{A R T I C L E I N F O}

\section{Article history:}

Received 16 October 2014

Received in revised form

17 December 2014

Accepted 19 December 2014

Available online $\mathrm{xxx}$

Keywords:

Counterfeit medicines

Insulin

Micellar electrokinetic chromatography

Quality control

Stability

\begin{abstract}
A B S T R A C T
A simple and efficient MEKC method was developed to simultaneously determine human insulin, its five analogues, the main degradation products and the excipients usually present in injection formulations. A very fast method with a total analysis time of $3 \mathrm{~min}$ was then successfully validated for the analysis of human insulin and the quality control of commercial formulations was carried out.
\end{abstract}

(c) 2015 Elsevier B.V. All rights reserved.

\section{Introduction}

Insulin is an important hormone secreted by pancreatic $\beta$-cells regulating principally glucose metabolism. Currently synthesised by recombinant DNA technology, this hormone is commonly administered by subcutaneous injection for the treatment of insulin-dependent diabetes mellitus. Human insulin consists of two peptide chains - A and B - containing 21 and 30 amino acid residues, respectively, and connected via two disulphide bridges (Fig. 1). As can be seen in this figure, the different insulin variants are quite similar since they differ only by one to three amino acids. Lispro, aspart and glulisin are rapid-acting analogues that mimic postprandial insulin secretion. Glargin and detemir are long-acting analogues that mimic basal insulin secretion.

Abbreviations: ACN, acetonitrile; BGE, background electrolyte; $\mathrm{CM}-\beta-\mathrm{CyD}$, carboxymethyl- $\beta-\mathrm{CyD}$; DNA, deoxyribonucleic acid; EOF, electroosmotic flow; HDAS- $\beta$-CyD, heptakis (2,3-di-O-acetyl-6-O-sulfo)- $\beta$-CyD; HDMS- $\beta$-CyD, heptakis (2,3-di-O-methyl-6-O-sulfo)- $\beta$-CyD; IS, internal standard; $\mathrm{N}$, number of theoretical plates, separation efficiency; OS- $\gamma$-CyD, octakis (2,3-dihydroxy-6-O-sulfo)- $\gamma$-CyD; $\mathrm{pI}$, isoelectric point; $\mathrm{SBE}-\beta-\mathrm{CyD}$, sulfobutylether- $\beta$-CyD; TM- $\beta$-CyD, heptakis $(2,3,6-$ tri-O-methyl)- $\beta$-CyD.

* Corresponding author. Tel.: +32 4366 4345; fax: +32 43664347 .

E-mail address: Marianne.fillet@ulg.ac.be (M. Fillet).
Protamine is sometimes associated with human insulin, lispro or aspart to provide an intermediate action profile [1]. The excipients of pharmaceutical injections are mainly meta-cresol and phenol.

Diabetes is one of the most common metabolic diseases in the world and the prevalence is increasing every year, especially for type 2 diabetes. A lot of insulin formulations are then produced; they are expensive and require a prescription. Therefore they are an important target for counterfeiting. Even if the proportion of counterfeit drugs is superior in developing countries, it is worth noting that it is affecting the whole world and more particularly the e-commerce in more economically developed countries. Counterfeited insulins contribute to therapeutic failures and in some cases can also lead to death. Therefore, it is essential for public health to strengthen the control of pharmaceutical products such as insulin formulations by developing efficient and easily applicable quality control methods.

The determination of insulin has been already described in the literature but most papers report immunochemical methods for the monitoring of biological samples [2-11]. Some instrumental analytical methods based on LC or CE were also developed for the analysis of pharmaceutical formulations but only for human insulin quantification in formulations without protamine [12-15]. Recently, CE and MEKC were applied to the separation of various insulin analogues [16-18]. Indeed, CE is an attractive technique 


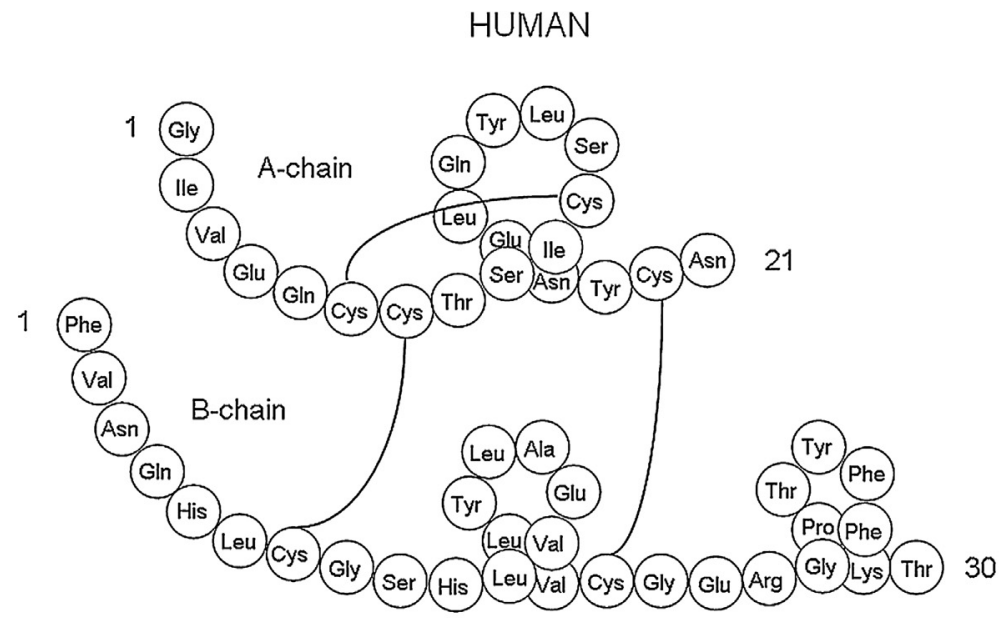

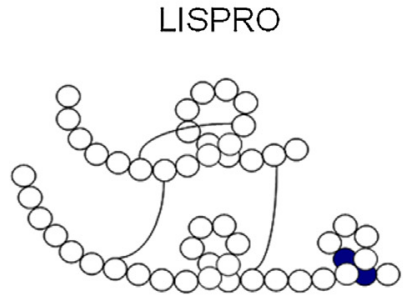

B28: Lys

B29: Pro

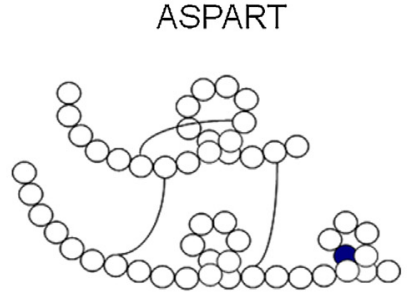

B28: Asp

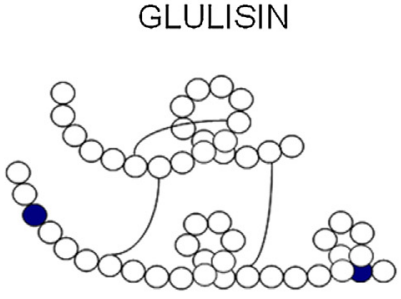

B3: Lys

B29: Glu
GLARGIN

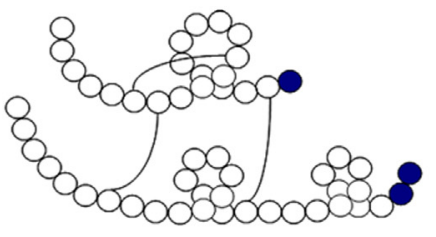

A21: Gly

B31-32: Arg

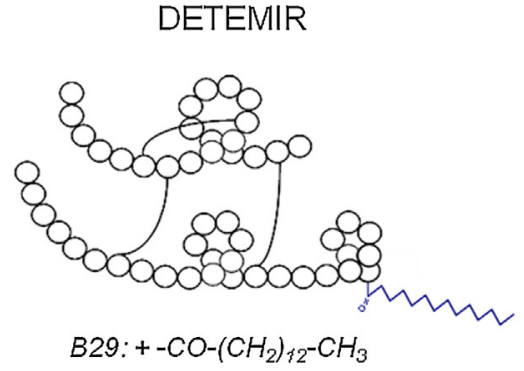

B30:/

Fig. 1. Structure of human insulin and its analogues.

with its well-known advantages such as simplicity, high separation efficiency, short analysis time and low sample and solvent consumption. It is considered as a powerful alternative to HPLC and is frequently used for the separation of large biomolecules [19,20].

The aim of this work was to develop an easy and fast MEKC method for the simultaneous determination of human insulin, its five analogues and the excipients usually present in commercial formulations. A stability study was also performed and degradation products could be separated with the same method. The method was shortened, adjusted and was then fully validated for human insulin analysis. It was also applied to the quality control of pharmaceutical formulations, including those containing protamine.

\section{Materials and methods}

\subsection{Chemicals and reagents}

Acetic acid, ammonia, $\mathrm{HCl}$ (37\%), $\mathrm{ACN}, \mathrm{SDS}$ and $\mathrm{ZnCl}_{2}$ were purchased from Merck (Darmstadt, Germany). Protamine, sodium benzoate, glycerol, phenol and meta-cresol were obtained from Sigma-Aldrich (St. Louis, MO, USA). $\gamma$-CyD was from Sigma-Aldrich. OS- $\gamma$-CyD was kindly provided by Professor G. Vigh (Texas A\&M University, TX, USA). CM- $\beta-C y D$, TM- $\beta-C y D$ and HDMS- $\beta-C y D$ were purchased from Cyclolab (Budapest, Hungary). SBE- $\beta-C y D$ was from CyDex Pharmaceuticals (Lenexa, KS, USA) and HDAS- $\beta$ CyD was obtained from Antek Instruments (Houston, TX, USA).

Human insulin standard was obtained from Sigma-Aldrich. Different pharmaceutical formulations were also used: Humuline $\mathrm{NPH}{ }^{\circledR}$ (human insulin) and Humalog ${ }^{\circledR}$ (insulin lispro) were obtained from Eli-Lilly (Indianapolis, IN, USA). Novomix 30® (insulin aspart) and Levemir ${ }^{\circledR}$ (insulin detemir) were purchased from Novo Nordisk (Bagsvaerd, Denmark). Insuman Rapid ${ }^{\circledR}$ (human insulin), Apidra ${ }^{\circledR}$ (insulin glulisin) and Lantus ${ }^{\circledR}$ (insulin glargin) were obtained from Sanofi Aventis (Bridgewater, NJ, USA). Actrapid $\AA$ and Mixtard $\AA$ (human insulins) were collected on the internet.

Ultra-pure water was supplied by a Milli- $Q$ equipment (Millipore, Bedford, MA, USA) and Chromafil ${ }^{\circledR}$ syringe filters 
$(0.20 \mu \mathrm{m})$ were purchased from Macherey-Nagel (Düren, Germany).

\subsection{Buffer and $B G E$}

The buffer was prepared by adding a solution of $50 \mathrm{mM}$ acetic acid to a solution of $50 \mathrm{mM}$ ammonia in order to reach $\mathrm{pH}$ 9.0. In the final conditions, the BGE was made by dissolving $20 \mathrm{mM}$ SDS in the buffer. Then, it was mixed with $A C N(13 \% \mathrm{v} / \mathrm{v})$ and the solution was filtered through a syringe filter.

To prepare BGE with other reagents mentioned in the study, the steps were similar as mentioned above.

\subsection{Sample preparation}

\subsubsection{BGE optimization and stability study}

Pharmaceutical formulations containing $100 \mathrm{IU} / \mathrm{ml}$ of insulin were used for method development. This corresponds to $3.50 \mathrm{mg} / \mathrm{ml}$ for human, lispro, aspart and glulisin insulins, $3.64 \mathrm{mg} / \mathrm{ml}$ for glargin insulin and $14.20 \mathrm{mg} / \mathrm{ml}$ for detemir insulin. Human, lispro, aspart, glulisin and glargin formulations were diluted 80 fold in $0.01 \mathrm{M} \mathrm{HCl}$ to obtain a concentration of approximately $50 \mu \mathrm{g} / \mathrm{ml}$ (43.75 or $45.50 \mu \mathrm{g} / \mathrm{ml}$ ). Unless otherwise mentioned, detemir formulation was diluted 160 fold in the same solvent $(88.75 \mu \mathrm{g} / \mathrm{ml})$. The mixture of the 6 insulin variants was also prepared as described above. Sodium benzoate was selected as IS and was prepared in $0.01 \mathrm{M} \mathrm{HCl}$. All analysis were performed in duplicate.

\subsubsection{Validation}

Calibration and validation standards of human insulin were prepared in $0.01 \mathrm{M} \mathrm{HCl}$, with $100 \mu \mathrm{g} / \mathrm{ml}$ IS and $10 \%$ ACN. Calibration standards were prepared without excipients while the excipients (phenol, meta-cresol, glycerol, $\mathrm{ZnCl}_{2}$ and protamine) were added in the validation standards. Three quantification levels were investigated (80, 100 and $120 \%$ ), the target level of $100 \%$ corresponding to $4 \mathrm{IU} / \mathrm{ml}(m=3)$. Four replicates were prepared at each level and three independent series were carried out $(k=3 ; n=4)$.

Calibration standards were used to set up the calibration model for the method while trueness, precision, accuracy and linearity were estimated using the validation standards.

\subsubsection{Quality control}

Standard solutions were prepared exactly like calibration standards. Four sample solutions were prepared by dissolution of the pharmaceutical formulation in $0.01 \mathrm{M} \mathrm{HCl}$ to obtain a concentration of $4 \mathrm{IU} / \mathrm{ml}$, taking into account the addition of IS and ACN $(n=4)$. Formulations containing human insulin (Actrapid $®$, Insuman Rapid ${ }^{\circledR}$ ) and human insulin with protamine (Mixtard ${ }^{\circledR}$, Humuline $\mathrm{NPH} \circledast$ ) contain $100 \mathrm{IU} / \mathrm{ml}$.

\subsection{Instrumentation}

All the experiments were carried out on a $\mathrm{HP}^{3 \mathrm{D}} \mathrm{CE}$ system (Agilent Technologies, Waldbronn, Germany) equipped with an autosampler, an on-column DAD and a temperature control system $\left(15-60{ }^{\circ} \mathrm{C} \pm 0.1^{\circ} \mathrm{C}\right.$ ). Chemstation (Hewlett-Packard, Palo Alto, CA, USA) was used for instrument control, data acquisition and data analysis. Fused silica capillaries were provided by ThermoSeparation Products (San Jose, CA, USA).

\subsubsection{BGE optimization and stability study}

Electrophoretic separations were carried out in uncoated fused silica capillaries with $50 \mu \mathrm{m}$ i.d. and $48.5 \mathrm{~cm}$ total length $(40 \mathrm{~cm}$ effective length). At the beginning of each working day, the capillary was washed with $1 \mathrm{M} \mathrm{NaOH}, 0.1 \mathrm{M} \mathrm{NaOH}$ and water for 10 min each. Before each injection, the capillary was successively washed with
$1 \mathrm{M} \mathrm{NaOH}$ for $2 \mathrm{~min}$, water for $1 \mathrm{~min}$ and was then equilibrated with the BGE for $4 \mathrm{~min}$. After each run, the capillary was washed with $0.01 \mathrm{M} \mathrm{HCl}$ for $5 \mathrm{~min}$ and water for $1 \mathrm{~min}$. Capillary wash cycles were performed at a pressure of approximately 1 bar. Injections were made by applying a pressure of 50 mbar for a period of $5 \mathrm{~s}$. During the run, the applied voltage was $20 \mathrm{kV}$ and the capillary was thermostated at $20^{\circ} \mathrm{C}$. Electropherograms were recorded at $200 \mathrm{~nm}$.

\subsubsection{Validation and quality control}

To reduce analysis time, the injection was made at the short capillary end ( $8.5 \mathrm{~cm}$ effective length). Moreover, the outlet electrode was immersed in $0.01 \mathrm{M} \mathrm{HCl}$ after each injection.

Validation data were processed using the e.noval@ 3.0 software (Arlenda, Liege, Belgium).

\section{Results and discussion}

\subsection{Preliminary studies}

A basic buffer composed of $50 \mathrm{mM}$ ammonium acetate ( $\mathrm{pH} 9.0$ ) was selected because it induced an important and stable EOF and it provided better peak shape than acidic buffers.

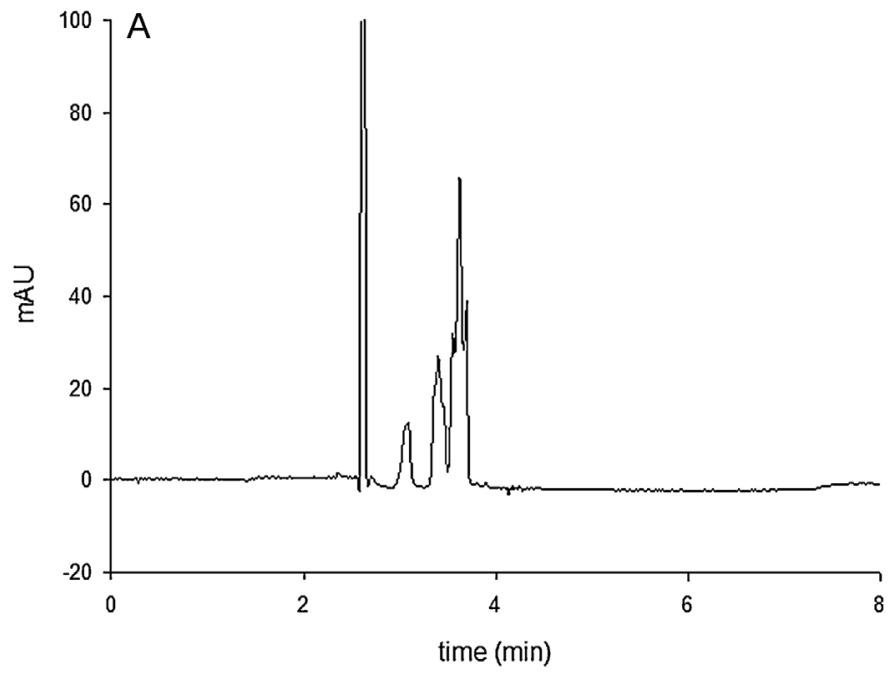

2

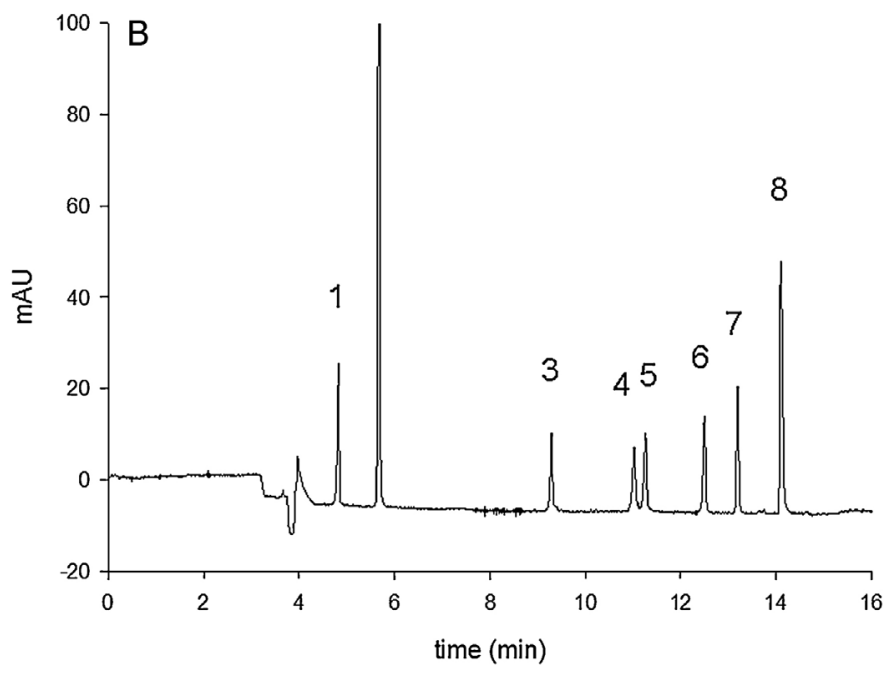

Fig. 2. Electropherogram of the six insulin formulations. (A) BGE: $50 \mathrm{mM}$ ammonium acetate $\mathrm{pH}$ 9.0. (B) BGE: $50 \mathrm{mM}$ ammonium acetate $\mathrm{pH} 9.0+50 \mathrm{mM}$ SDS + 15\% ACN. Other conditions are described in Section 2.3.1. Peaks: $1=$ phenol, $2=\mathrm{m}$-cresol, $3=$ aspart, 4 = human, 5 = lispro, 6 = glulisin, 7 = glargin, 8 = detemir. 
As some formulations contained protamine, the sample dissolution medium was also optimised. Indeed, protamine is a basic and aliphatic protein which forms with insulin and zinc a complex insoluble at neutral $\mathrm{pH}$. An acidic $\mathrm{pH}$ was then required to solubilise protamine, but also glargin. A solution made of $0.01 \mathrm{M} \mathrm{HCl}$ was finally chosen as dissolution and dilution solvent.

\subsection{BGE optimization for the separation of human insulin and its analogues}

Fig. 2A shows the electropherogram of the mixture containing six pharmaceutical formulations (human insulin and its five analogues) under the conditions mentioned in the preliminary studies. As can be seen in this figure, all the analogues were not separated. As their molecular weights $(\sim 5800 \mathrm{Da})$ and pIs $(\sim 5.5)$ are quite similar, they have almost identical electrophoretic mobilities and their separation by conventional CE is not easy. Therefore, some additives were used to improve the separation.

First, different CyD were chosen to investigate their selectivity towards insulins according to their size and their different substituents: $\gamma$-CyD, OS- $\gamma$-CyD, CM- $\beta-C y D, T M-\beta-C y D, H D M S-\beta-C y D$, SBE- $\beta-C y D$ and HDAS- $\beta-C y D$. The CyD concentrations tested (15 and $30 \mathrm{mM}$ ) are in agreement with those commonly used in our laboratory. The migration profile was modified by some of them but this was not sufficient to obtain a complete resolution (data not shown).

MEKC was then investigated. SDS is the most commonly used surfactant and was tested at different concentrations (35 and $50 \mathrm{mM})$ in the presence - or not - of an organic modifier $(0-20 \%$ ACN).

The addition of $50 \mathrm{mM}$ SDS led to the separation of the two major excipients, phenol and meta-cresol, but not of all insulins. The same observation was made with $10 \% \mathrm{ACN}$ v/v added to the SDS system. Good results were obtained with $15 \%$ ACN since the six insulins were completely separated within $15 \mathrm{~min}$ (see Fig. 2B). It is worth noting that a multivariate approach could not be applied in this study because of too extreme responses (with on/off effects) when a factor was modified.

These results are in accordance with previous reports which indicated that small peptides could be successfully separated by MEKC [21-24] and that the addition of organic solvent was required to separate closely related peptides with more than 20 amino acid residues $[25,26]$. Indeed, proteins strongly interact with surfactants and tend to form complexes. The organic solvent added to the micellar solution can prevent this interaction.

The optimized condition led to the following insulins migration order: aspart, human, lispro, glulisin, glargin and detemir. Indeed, with its C14 fatty acid chain, detemir is the most hydrophobic analogue and thus interacts more strongly with the surfactant. For the other compounds, a MEKC system with an organic modifier makes the interpretation very complex as a lot of parameters are involved in the migration behaviour [27]. Indeed the interactions depend on the $\log \mathrm{P}$ and the charge of the analyte (possible ion-pair formation). However, the presence of ACN in the BGE reduces the interactions with the micelles and the migration behaviour can be significantly modified from one analyte to the others [27]. Attention can be paid to the resolution obtained between human and lispro insulins which differ only by the inversion of two amino acids (Fig. 1). This suggests that the secondary structure of the protein could also play an essential role in the interaction with the surfactant, probably because of different expositions of hydrophobic sites. The separation of human and lispro insulins was also achieved thanks to the high peak efficiency $(N \approx 150000)$.

\subsection{Stability study}

A stability study was carried out on the pharmaceutical formulations stored in a refrigerator $\left(4-8{ }^{\circ} \mathrm{C}\right)$, at room temperature $\left(20-25^{\circ} \mathrm{C}\right)$ and at $37 \pm 1^{\circ} \mathrm{C}$ during $3,7,14,21$ and 28 days. The percentage of degradation was estimated by calculating the peak area ratio between the possible degradation product and the sum of the insulin and the possible degradation product. No degradation was detected after 28 days irrespective of the temperature (data not shown).

The insulin stability was also investigated in formulations diluted in $0.01 \mathrm{M} \mathrm{HCl}$ and stored $24 \mathrm{~h}, 48 \mathrm{~h}$ and 6 days at the three previously mentioned temperatures (see Fig. 3). No degradation was observed for the samples kept in refrigerator. A small degradation was detected for glulisin and detemir stored at room temperature but only after 6 days. For the samples stored at $37^{\circ} \mathrm{C}$, degradation was already observed after $24 \mathrm{~h}$ for all insulins except aspart and glargin. This suggests that an acidic $\mathrm{pH}$ and a rather high temperature promote degradation. Degradation increased after $48 \mathrm{~h}$ for the same insulins and increased again after 6 days for all insulins except glargin. This exception can be explained by the fact that the main degradation of insulin originates from deamidation at residue A-21 [28]. At this position, glargin has the amino acid Gly instead of Asn (Fig. 1). Therefore, A-21 deamidation could not occur for glargin insulin. Fig. 4 demonstrates the selectivity of the method for impurity detection.

The stability of human insulin standard was also studied after dilution in $0.01 \mathrm{M} \mathrm{HCl}$ and storage for $24 \mathrm{~h}, 48 \mathrm{~h}$ and 6 days at the three previously mentioned temperatures. Despite the absence of preservatives, the degradation profile of human insulin standard looked quite similar compared to that of the formulation (see Fig. 3 ).

In summary, samples seem to remain stable after 24 or $48 \mathrm{~h}$ if stored at a maximal temperature of $25^{\circ} \mathrm{C}$.

\subsection{Method validation for routine quality control of formulations containing human insulin}

To demonstrate the applicability of our approach for routine analysis, a method validation was carried out for the quantification of human insulin.

Before the validation and to reduce analysis time for routine quality control, the previously developed method was shortened. The injection was made at the short capillary end leading to a 5fold reduction of the analysis time. Small adjustments of the BGE composition (20 mM SDS and 13\% ACN) were provided in order to obtain satisfactory selectivity with the degradation product (cf. Fig. 5A). $10 \%$ ACN was also added to the samples to guarantee the stability of insulin and prevent its adsorption.

It is worth noting that in those conditions, the separation of the 6 insulins within 3 min was also very good except that between human insulin and lispro (Fig. 5B). It was considered sufficient to perform identification, however, the initial method could be easily applied to confirm the identification if in doubt. Selectivity of the analytical method was assessed by analyzing reconstituted blank solution (containing the excipients included protamine but without insulin). No endogenous source of interference was observed at the migration time of human insulin.

In order to quantify one of these insulins, sodium benzoate was chosen as IS. The normalized peak area ratios (i.e. areas divided by migration times) between the active compound and the IS were calculated.

\subsubsection{Selection of the calibration model}

The acceptance limits were set at $\pm 10 \%$ (cf. requirement of the European Pharmacopea for Human Insulin preparations) and the maximum risk $(1-\beta)$ to obtain results outside these acceptance 
$4-8^{\circ} \mathrm{C}$

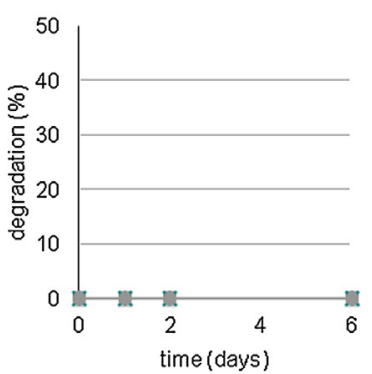

$20-25^{\circ} \mathrm{C}$

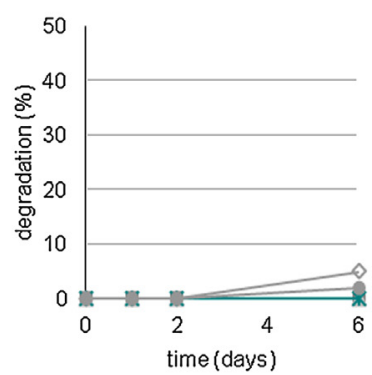

$37^{\circ} \mathrm{C}$

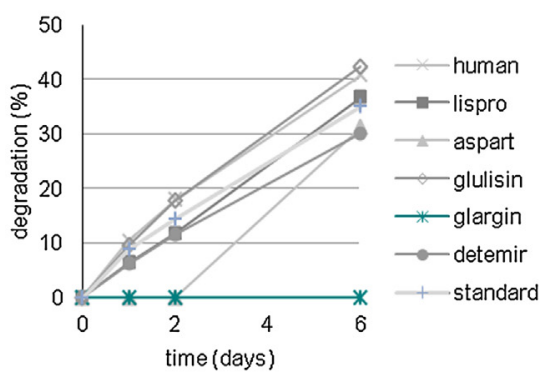

Fig. 3. Stability studies showing the percentage of degradation as a function of time. Pharmaceutical formulations diluted in $0.01 \mathrm{M} \mathrm{HCl}$.

limits was set at 5\%. Different regression models were fitted to the calibration standards and linear regression was chosen as the most appropriate response function (Fig. 6).

\subsubsection{Other validation criteria}

Table 1 presents the validation results of human insulin. Trueness of the method was excellent as the upper relative bias of the method was $1.272 \%$. The RSD values for repeatability and intermediate precision were satisfactory (below 3\%), demonstrating a good precision. The method was accurate since the lower and upper

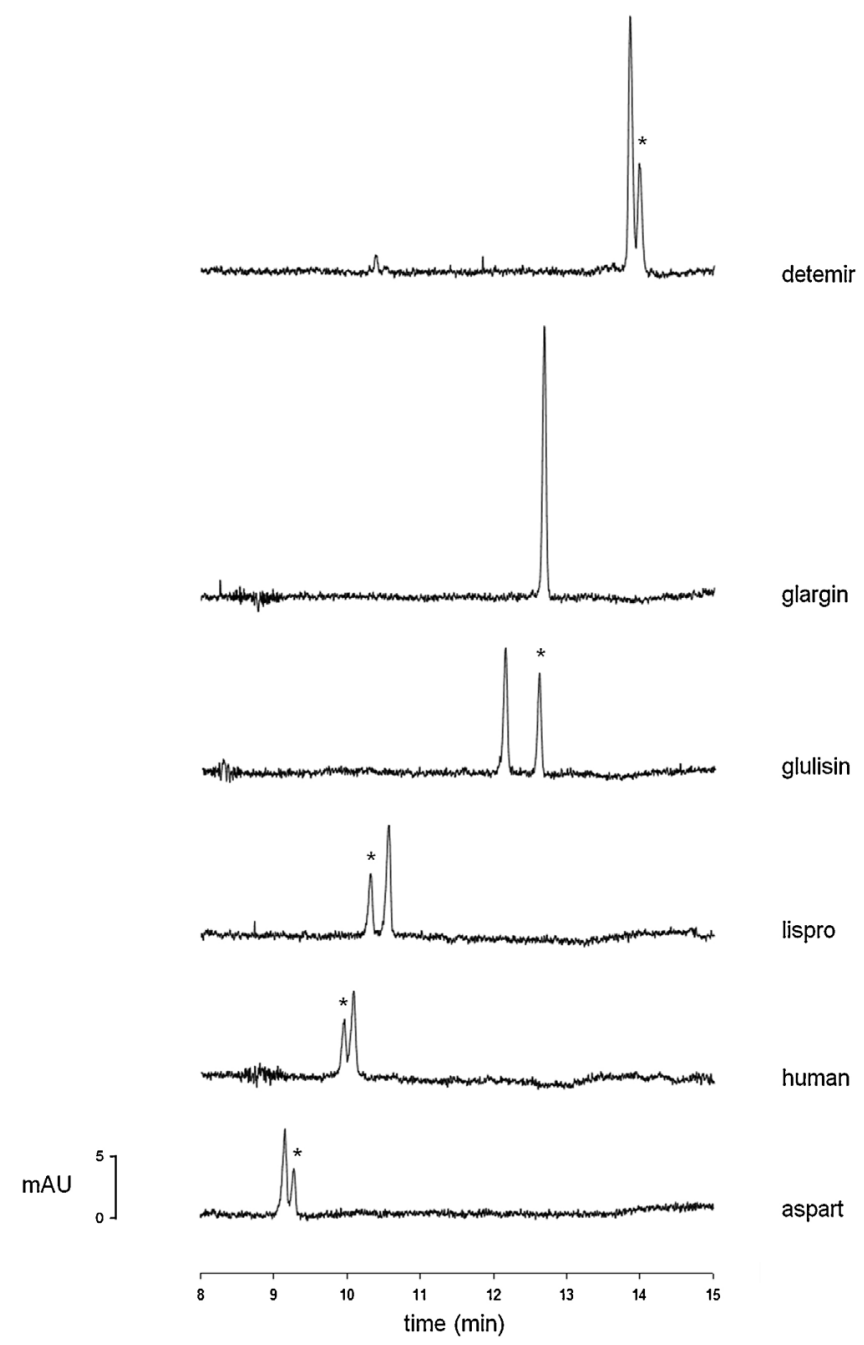

Fig. 4. Effect of 6 days storage in $\mathrm{HCl} 0.01 \mathrm{M}$ and at $37^{\circ} \mathrm{C}$ on the six insulin formulations. BGE: $50 \mathrm{mM}$ ammonium acetate pH $9.0+50 \mathrm{mM}$ SDS + 15\% ACN. Other conditions are described in Section 2.3.1. Peaks: ${ }^{*}=$ degradation product. tolerance limits did not exceed the acceptance limits of $10 \%$ over the considered concentration range. For all series, a regression line was fitted to the back-calculated concentrations of the validation standards as a function of the introduced concentrations. The results attesting the method linearity, namely the regression
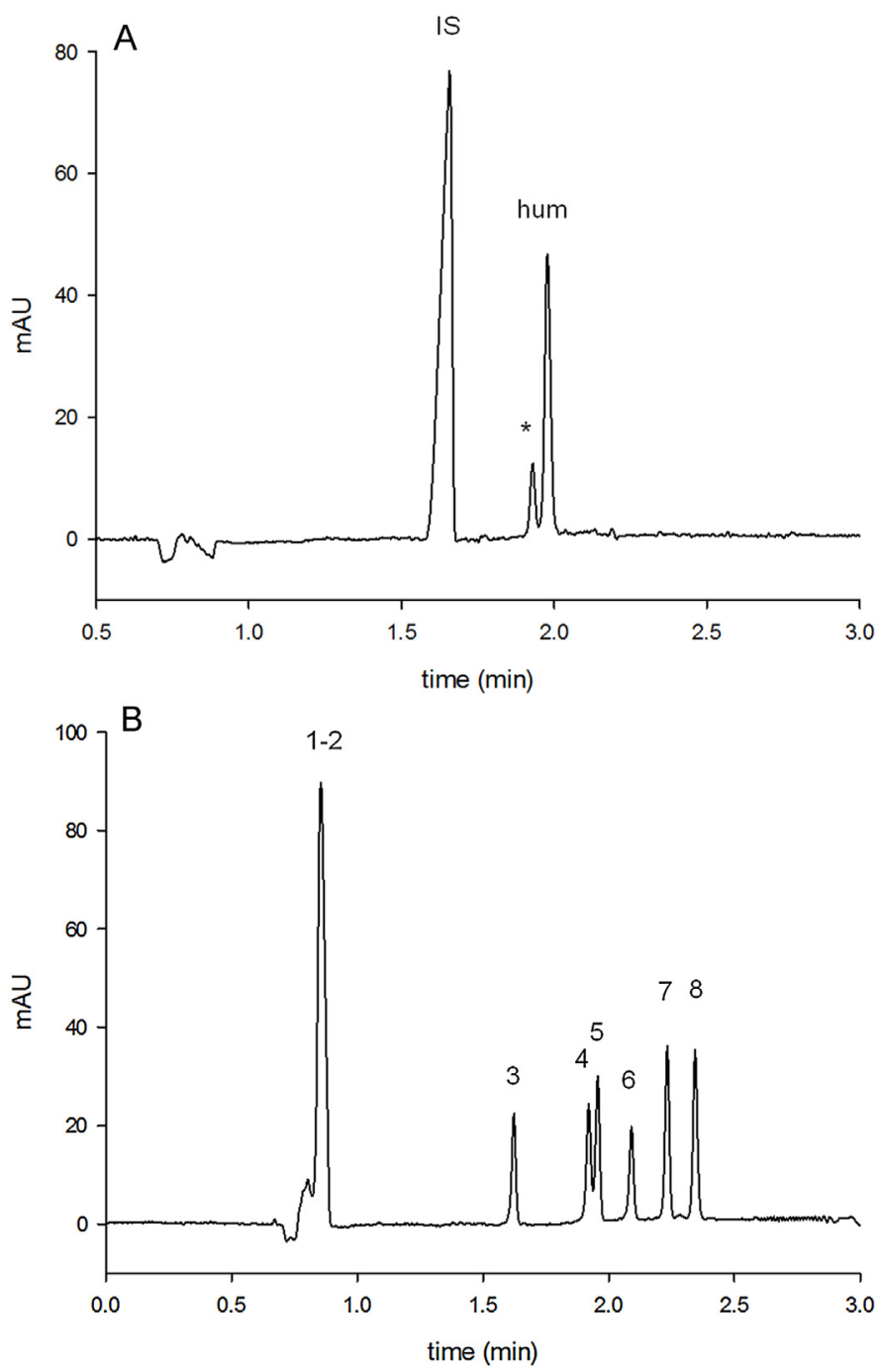

Fig. 5. (A) Electropherogram of human insulin with its degradation product (2 days storage in $\mathrm{HCl} 0.01 \mathrm{M}$ and at $37^{\circ} \mathrm{C}$ ). Peaks: IS = sodium benzoate (IS), * = degradation product, hum = human insulin. (B) Electropherogram of the six insulin formulations obtained after analysis at the short capillary end. BGE: $50 \mathrm{mM}$ ammonium acetate pH 9.0 + 20 mM SDS + 13\% ACN. Peaks: $1=$ phenol, $2=\mathrm{m}$-cresol, $3=$ aspart, $4=$ human, 5 = lispro, 6 = glulisin, 7 = glargin, 8 = detemir. Other conditions are described in Section 2.3.1. 


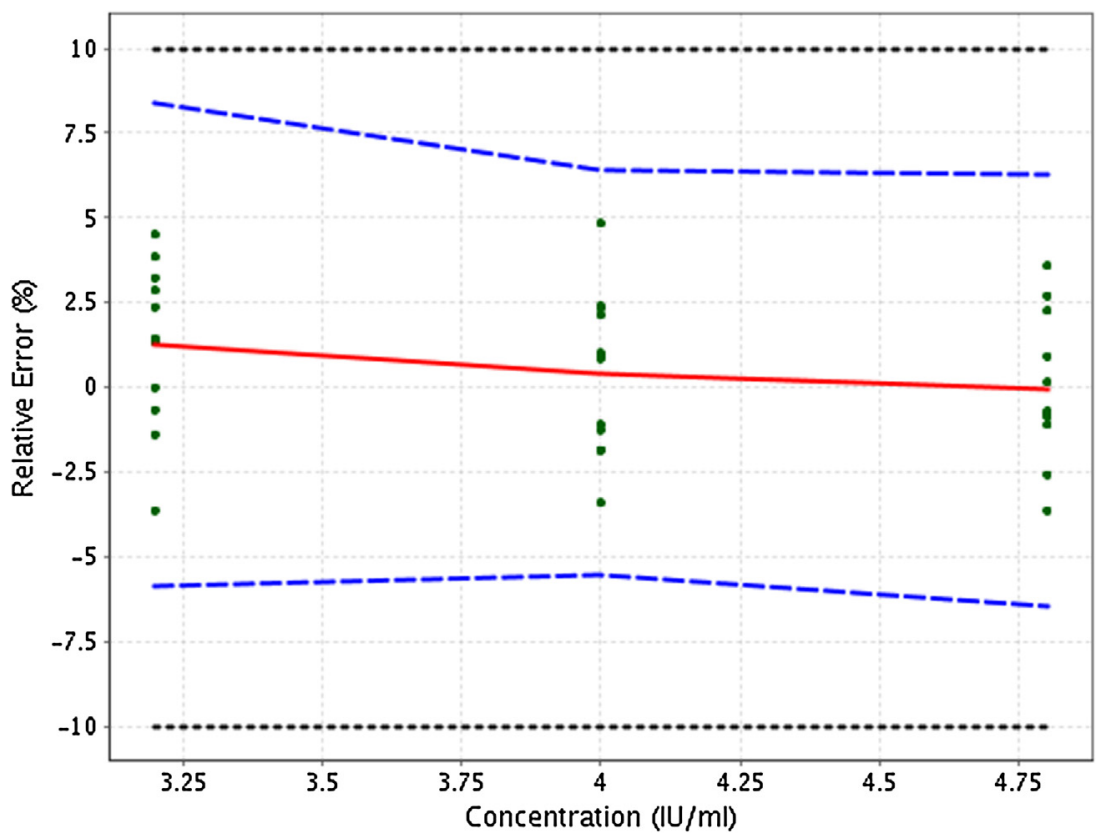

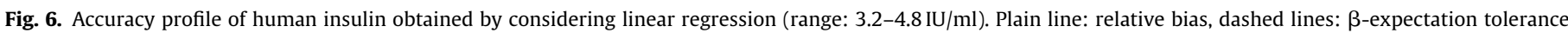
limits, dotted curves: acceptance limits and dots: relative back-calculated concentrations.

equation corresponding to that relationship with the coefficient of determination, are presented in Table 1 . The LOD was estimated at $0.43 \mathrm{IU} / \mathrm{ml}$ using the intercept of the calibration model and the residual variance of the regression. In this case, the LOQ was the lowest concentration level, $3.2 \mathrm{IU} / \mathrm{ml}$.

\subsection{Quality control of human insulin formulations}

A qualitative and quantitative analysis of four different pharmaceutical formulations (Actrapid $\AA$, Mixtard ${ }^{\circledR}$, Humuline $\mathrm{NPH} \circledast$ and Insuman Rapid ${ }^{\circledR}$ ) was carried out according to the validated method. Four standard solutions at each level (80, 100 and 120\%) and four samples of each formulation at $4 \mathrm{IU} / \mathrm{ml}$ were independently prepared. To make the conversion from IU to $\mathrm{mg}$ and

Table 1

Validation results of human insulin $(k=3 ; m=3 ; n=4)$.

\begin{tabular}{llll}
\hline & Day 1 & Day 2 & Day 3 \\
\cline { 2 - 4 } Response function & & & \\
\hline Slope & 0.1643 & 0.1594 & 0.1559 \\
Intercept & -0.04498 & -0.01421 & -0.005656 \\
$r^{2}$ & 0.9795 & 0.9739 & 0.9883 \\
& Level 1 & Level 2 & Level 3 \\
Trueness & & & \\
Relative bias (\%) & 1.272 & 0.4236 & -0.06906 \\
Precision & & & \\
Repeatability (RSD, \%) & 1.838 & 2.140 & 1.665 \\
Intermediate precision (RSD, \%) & 2.534 & 2.426 & 2.275 \\
Accuracy & & & \\
$\beta$-expectation tolerance limits (\%) & $-5.877 / 8.421$ & $-5.542 / 6.389$ & $-6.445 / 6.307$ \\
Linearity & & & \\
Range (IU/ml) & & & \\
Slope & & & \\
Intercept & $3.2-4.8$ & & \\
$r^{2}$ & 0.9725 & & \\
LOD (IU/ml) & 0.1282 & & \\
LOQ (IU/ml) & 0.9814 & & \\
\hline
\end{tabular}

$k$ : number of days of experiments (series), $m$ : number of concentration levels, $n$ : number of replicates per concentration level and per series.
Table 2

Analytical results for the quantification of human insulin in pharmaceutical formulations.

\begin{tabular}{llll}
\hline $\begin{array}{l}\text { Pharmaceutical } \\
\text { formulations }\end{array}$ & $\begin{array}{l}\text { Concentration } \\
\text { found }(\mathrm{IU} / \mathrm{ml})\end{array}$ & $\begin{array}{l}\text { Percentage of the } \\
\text { claimed content }(\%)\end{array}$ & $\begin{array}{l}\text { Repeatability } \\
\text { (RSD, \%) }\end{array}$ \\
\hline $\begin{array}{l}\text { Actrapid } \AA \\
\text { Mixtard }{ }^{\circledR}\end{array}$ & 3.90 & 97.3 & 1.34 \\
$\begin{array}{l}\text { Humuline } \\
\text { NPH® }\end{array}$ & 4.16 & 103.9 & 1.05 \\
Insuman & 4.29 & 107.2 & 0.91 \\
Rapid® & 4.02 & 100.5 & 3.84 \\
\hline
\end{tabular}

therefore to know which weight of the standard is needed, the assay in IU/mg and the loss on drying of this standard must be taken into account.

The regression equation was used to calculate the concentration of the samples and then the percentage of the claimed content. The mean of the percentages and the RSDs are given in Table 2. All the tested formulations were inside the limits of $90-110 \%$.

\section{Concluding remarks}

In the present study, MEKC was used to simultaneously analyse human insulin and its five analogues (lispro, aspart, glulisin, glargin and detemir). A method was developed using the following BGE: $50 \mathrm{mM}$ ammonium acetate $\mathrm{pH}$ 9.0,50 mM SDS and 15\% ACN. The six insulins and the two major excipients of pharmaceutical formulations could be separated within $15 \mathrm{~min}$. This method also exhibited selectivity regarding their principal degradation products, so that the samples stability could be studied as a function of time and temperature of the storage.

A fast method with an analysis time of 3 min was obtained by injecting at the short capillary end and by using the following BGE: $50 \mathrm{mM}$ ammonium acetate $\mathrm{pH}$ 9.0, $20 \mathrm{mM}$ SDS and 13\% ACN. This method was fully validated for human insulin over the concentration range of 3.2 and $4.8 \mathrm{IU} / \mathrm{ml}$, with acceptance limits of $10 \%$ and a risk of $5 \%$. Then, the quality control of formulations containing human insulin, including those with protamine, was successfully achieved. These investigations demonstrate the 
interesting ability of capillary electrophoresis for quantification of intact biomolecules.

\section{Acknowledgements}

Many thanks are due to the Fonds National de la Recherche Scientifique (FNRS, Belgium) and the Fonds Léon Fredericq (Liege, Belgium) for their financial support.

\section{References}

[1] S. Madsbad, Insulin and new insulin analogues with focus on type 2 diabetes, in: C.E. Mogensen (Ed.), Pharmacotherapy of Diabetes: New Developments, Springer, US, 2007, pp. 53-65.

[2] W. Tong, E.S. Yeung, Determination of insulin in single pancreatic cells by capillary electrophoresis and laser-induced native fluorescence, J. Chromatogr. B: Biomed. Appl. 685 (1996) 35-40.

[3] I. German, R.T. Kennedy, Rapid simultaneous determination of glucagon and insulin by capillary electrophoresis immunoassays, J. Chromatogr. B: Biomed. Sci. Appl. 742 (2000) 353-362.

[4] V. Solinova, V. Kasicka, D. Koval, T. Barth, A. Ciencialova, L. Zakova, Analysis of synthetic derivatives of peptide hormones by capillary zone electrophoresis and micellar electrokinetic chromatography with ultraviolet-absorption and laser-induced fluorescence detection, J. Chromatogr. B: Analyt. Technol. Biomed. Life Sci. 808 (2004) 75-82.

[5] I. Le Potier, G. Franck, C. Smadja, S. Varlet, M. Taverna, In-capillary derivatization approach applied to the analysis of insulin by capillary electrophoresis with laser-induced fluorescence detection, J. Chromatogr. A 1046 (2004) 271-276.

[6] S. Descroix, I. Le Potier, C. Niquet, N. Minc, J.L. Viovy, M. Taverna, In-capillary non-covalent labeling of insulin and one gastrointestinal peptide for their analyses by capillary electrophoresis with laser-induced fluorescence detection, J. Chromatogr. A 1087 (2005) 203-209.

[7] M. Thevis, A. Thomas, P. Delahaut, A. Bosseloir, W. Schanzer, Qualitative determination of synthetic analogues of insulin in human plasma by immunoaffinity purification and liquid chromatography-tandem mass spectrometry for doping control purposes, Anal. Chem. 77 (2005) 3579-3585.

[8] C. Guillo, M.G. Roper, Two-color electrophoretic immunoassay for simultaneous measurement of insulin and glucagon content in islets of Langerhans Electrophoresis 29 (2008) 410-416.

[9] J.F. Dishinger, K.R. Reid, R.T. Kennedy, Quantitative monitoring of insulin secretion from single islets of Langerhans in parallel on a microfluidic chip, Anal. Chem. 81 (2009) 3119-3127.

[10] C. Guillo, T.M. Truong, M.G. Roper, Simultaneous capillary electrophoresis competitive immunoassay for insulin, glucagon, and islet amyloid polypeptide secretion from mouse islets of Langerhans, J. Chromatogr. A 1218 (2011) 4059-4064

[11] C. Hess, A. Thomas, M. Thevis, B. Stratmann, W. Quester, D. Tschoepe, B. Madea, F. Musshoff, Simultaneous determination and validated quantification of human insulin and its synthetic analogues in human blood serum by immunoaffinity purification and liquid chromatography-mass spectrometry, Anal. Bioanal. Chem. 404 (2012) 1813-1822.

[12] A. Kunkel, S. Günter, C. Dette, H. Wätzig, Quantitation of insulin by capillary electrophoresis and high-performance liquid chromatography. Method comparison and validation, J. Chromatogr. A 781 (1997) 445-455.

[13] P. Moslemi, A.R. Najafabadi, H. Tajerzadeh, A rapid and sensitive method for simultaneous determination of insulin and A21-desamido insulin by highperformance liquid chromatography, J. Pharm. Biomed. Anal. 33 (2003) 45-51.

[14] B. Deng, Z. Liu, G. Luo, H. Ma, M. Duan, Rapid quantitative determination and assessment of insulin in oil formulation by micellar electrokinetic capillary chromatography, J. Pharm. Biomed. Anal. 27 (2002) 73-80.

[15] A. Staub, S. Rudaz, J.L. Veuthey, J. Schappler, Multiple injection technique for the determination and quantitation of insulin formulations by capillary electrophoresis and time-of-flight mass spectrometry, J. Chromatogr. A 1217 (2010) 8041-8047.

[16] K. Ortner, W. Buchberger, M. Himmelsbach, Capillary electrokinetic chromatography of insulin and related synthetic analogues, J. Chromatogr. A 1216 (2009) 2953-2957.

[17] M. Haunschmidt, K. Ortner, K. Hainz, E. Bradt, L. Sternbauer, W. Buchberger C.W. Klampfl, Investigations on the migration behavior of insulin and related synthetic analogues in CZE, MEKC and MEEKC employing different surfactants, Electrophoresis 31 (2010) 1560-1564.

[18] H.H. Yeh, H.L. Wu, C.Y. Lu, S.H. Chen, Simultaneous determination of regular insulin and insulin aspart by capillary zone electrophoresis and application in drug formulations, J. Pharm. Biomed. Anal. 53 (2010) 145-150.

[19] N.F. Visser, M. van Harmelen, H. Lingeman, H. Irth, On-line SPE-CE for the determination of insulin derivatives in biological fluids, J. Pharm. Biomed. Anal. 33 (2003) 451-462.

[20] A. Staub, D. Guillarme, J. Schappler, J.L. Veuthey, S. Rudaz, Intact protein analysis in the biopharmaceutical field, J. Pharm. Biomed. Anal. 55 (2011) 810-822.

[21] H.J. Liu, R.E. Strong, I.S. Krull, S.A. Cohen, Homogeneous preparation of fluorescent-derivatized insulin and its application to competitive chromatographic immunoassays, Anal. Biochem. 298 (2001) 103-111.

[22] H. Nishi, S. Terabe, Micellar electrokinetic chromatography perspectives in drug analysis, J. Chromatogr. A 735 (1996) 3-27.

[23] B. Stanley, K.A. Mehr, T. Kellock, J.D. Van Hamme, K.K. Donkor, Separation and determination of closely related lantibiotics by micellar electrokinetic chromatography, J. Sep. Sci. 32 (2009) 2993-3000.

[24] Y. Wu, J. Xie, F. Wang, Z. Chen, Separation of small molecular peptides with same amino acid composition but different sequences by capillary electrophoresis, J. Sep. Sci. 32 (2009) 437-440.

[25] T. Yashima, A. Tsuchiya, O. Morita, S. Terabe, Separation of closely related large peptides by micellar electrokinetic chromatography with organic modifiers, Anal. Chem. 64 (1992) 2981-2984.

[26] C. Arcelloni, L. Falqui, S. Martinenghi, A.E. Pontiroli, R. Paroni, Capillary electrophoresis for simultaneous quantification of human proinsulin, insulin and intermediate forms, Electrophoresis 19 (1998) 1475-1477.

[27] C. Lamalle, A.C. Servais, I. Fradi, J. Crommen, M. Fillet, Micellar electrokinetic chromatography systems for the separation of mixtures of charged and uncharged compounds, J. Sep. Sci. 35 (2012) 1933-1939.

[28] J. Brange, L. Langkjaer, Chemical stability of insulin. 3. Influence of excipients, formulation, and pH, Acta Pharm. Nord. 4 (1992) 149-158. 